UDK 811.163.42’374

Prethodno priopćenje

Rukopis primljen 26. VIII. 2019.

Prihvaćen za tisak 25. XI. 2019.

doi.org/10.31724/rihjj.46.2.16

\title{
Virna Karlić
}

Filozofski fakultet Sveučilišta u Zagrebu Ulica Ivana Lučića 3, HR-10000 Zagreb vkarlic@ffzg.hr

\section{Petra Bago}

Filozofski fakultet Sveučilišta u Zagrebu Ulica Ivana Lučića 3, HR-10000 Zagreb pbago@ffzg.hr

\section{PRAGMATIKA I LEKSIKOGRAFIJA: DEIKTICI KAO IZAZOV SUVREMENE LEKSIKOGRAFIJE}

U radu se analiziraju leksikografski opisi deiktičkih izraza u suvremenim jednojezičnim rječnicima hrvatskoga jezika. Posebna pozornost posvećena je deikticima „na granici punoznačnosti” (Kordić 2002) - skupini leksema čiji opis leksikografima predstavlja poseban izazov jer se njihovo puno značenje/referent uspostavlja tek u kontekstu realizacije konkretnoga iskaza. Rad je podijeljen u tri dijela. Uvodno poglavlje posvećeno je definiciji, obilježjima i vrstama deikse, dok se u središnjemu dijelu rada analiziraju primjeri rječničkih definicija osobnih (ja), društvenih ( $t i / V i)$, mjesnih (ovdje), vremenskih (sada) i diskursnih (sada i ovdje) deiktika iz triju hrvatskih jednojezičnika (Hrvatski jezični portal, Rječnik hrvatskoga jezika Vladimira Anića te Veliki rječnik hrvatskoga standardnog jezika skupine autora). U završnome se poglavlju iznose zaključci provedene analize te se ukazuje na prednosti primjene (korpusne) pragmatike u leksikografiji.

\section{Uvod: definicija, obilježja i vrste deikse}

Pragmatika je lingvistička disciplina koja se bavi proučavanjem jezične upotrebe u kontekstu govornoga događaja te odnosom konteksta i raznih aspekata jezične interpretacije (The Cambridge Dictionary of Philosophy 1999: 675). Deiksa pripada domeni pragmatike jer predstavlja izravnu vezu između jezične strukture 
i konteksta jezične upotrebe (Levinson 1983: 55). Fillmore (1975) deiktike definira kao jezične jedinice determinirane (a potom i interpretirane) okolnostima u kojima se odvija iskaz: (1) identitetom sudionika govornoga događaja (osobna deiksa: Ti si mi najbolji prijatelj.), (2) njihovom lokacijom (mjesna deiksa: $\boldsymbol{O} \boldsymbol{v}$ dje je hladno.), (3) vremenom odvijanja govornoga događaja (vremenska deiksa: Sada sam dobro.), (4) društvenim statusom sugovornika i njihovim međusobnim odnosom (društvena deiksa: Hvala ti/Vam!) te (5) pozicioniranošću u diskursu (diskursna deiksa: Ovdje se opisuju vrste deikse.).

Deiksa je jezični fenomen ukorijenjen u ljudskome tjelesnom iskustvu (Diessel 2012: 2). Prema teoriji uma jedan od glavnih preduvjeta za razvoj verbalne komunikacije čovjekova je sposobnost da se postavi u tuđu perspektivu, koja se odražava u jezičnoj strukturi i upotrebi (Tomasello 2006). Ta je sposobnost presudna za ovladavanje deiksom, jer su deiktični izrazi ,usidreni” u specifične točke komunikacijskoga čina. Sidrište ili centar koordinatnoga sustava deikse u prototipnim slučajevima predstavlja govornik, njegova lokacija te vrijeme iznošenja iskaza (Levinson 1983: 63-64). U nekim slučajevima deiktički centar (točka gledišta) može biti pomaknut (deiktička projekcija) na drugu, stvarnu ili fiktivnu osobu (Lyons 1977: 579). Dvije su vrste upotrebe deiktičnih izraza - simbolička i gestovna (Fillmore 1971). Dok je za razumijevanje simbolične deikse dovoljno poznavati prostorne i vremenske odrednice iskaza (Ovdje je hladno.), gestovna je deiksa obavezno popraćena paralingvističkim signalom poput pokreta rukom, glavom ili pogledom (Natoči mi ovoliko vina.).

Deiktici su izrazi s ,ugrađenim kontekstnim elementima” koji mogu biti specificirani aspektima situacijskoga i diskursnoga konteksta (Levinson 2004: 14). Kad upućuju na referent poznat iz diskursa (Stigli su na Vis. Ondje je jako lijepo.), njihova upotreba nije deiktička, već koreferencijalna. S druge strane, nedeiktični izrazi mogu biti u deiktičkoj upotrebi ako su modificirani/determinirani nekim deiktičnim jezičnim sredstvom (Vidjeli smo se ovoga jutra.).

Deiktici pripadaju skupini leksema čiji opis leksikografima predstavlja poseban izazov jer se njihovo puno značenje/referent uspostavlja tek u kontekstu realizacije konkretnoga iskaza. Tako primjerice iskaz s višestrukim deiktičnim izrazima (npr. Ja sam sada ovdje.) poprima puno značenje tek kad/ako je primatelj upoznat s identitetom govornika te mjestom i vremenom iznošenja iskaza. $\mathrm{Na}$ pitanje kako definirati značenje i opisati funkcije ovakvih leksema - ovisnih o 
ko(n)tekstu govornoga događaja - hrvatska leksikografija za sada odgovara rječničkim opisima u kojima izostaje (nužna) pragmatička perspektiva.

\section{Analiza rječničke građe: ciljevi, građa, metodologija}

U radu se analizira leksikografska obrada deiktika u trima hrvatskim jednojezičnim rječnicima: (1) Hrvatskome jezičnom portalu (u nastavku teksta HJP), (2) Rječniku hrvatskoga jezika (1998) Vladimira Anića (u nastavku teksta RHJ) te (3) Velikome rječniku hrvatskoga standardnog jezika (2015) skupine autora (u nastavku teksta VRH). Posebna pozornost posvećena je rječničkim definicijama primarnoga značenja deiktičnih riječi te prikazu pragmatičkih informacija o njihovu značenju i upotrebi u sklopu rječničke natuknice. ${ }^{2} \mathrm{Za}$ analizu su izabrani reprezentativni primjeri osobnih ( $j a / t i)$, društvenih ( $t i \neq V i)$, mjesnih (ovdje), vremenskih (sada) i diskursnih (sada i ovdje) deiktika. Analizi primjera svakoga pojedinog tipa deiktika prethodi kratak prikaz pripadajuće vrste deikse i njezinih obilježja te mehanizama kodiranja.

\subsection{Personalna i socijalna deiksa: analiza primjera}

Personalna deiksa podrazumijeva jezično kodiranje uloga sudionika u govornome događaju, a najčešća sredstva njezina izražavanja osobne su zamjenice i njima odgovarajući glagolski oblici. Prvo lice podrazumijeva gramatikalizaciju govornikove autoreference, drugo lice govornikovo referiranje na jednoga ili više sugovornika kojima se obraća, a treće lice govornikovo referiranje na osobe koje ne sudjeluju izravno u govornome događaju (Levinson 1983: 68). Iako se u pragmatičkoj literaturi često navodi da je glavna funkcija osobne deikse identificiranje sudionika govornoga događaja, Diessel (2012) ističe da osobni deiktici najčešće služe autoreferiranju ili naglašavanju govornikove uloge u iskazu.

\footnotetext{
1 Rječnička baza Hrvatskoga jezičnog portala nastala je na temelju rječničkih i leksikografskih izdanja Novoga Libera: Rječnik hrvatskoga jezika (Anić - I. izdanje 1991., II. izdanje 1994. i III. izdanje 1998.); Pravopis hrvatskoga jezika (Anić i Silić 2001); Veliki rječnik hrvatskoga jezika (Anić 2003, ur. Ljiljana Jojić); Kronologija - Hrvatska, Europa, Svijet (grupa autora, ur. Goldstein); Rječnik stranih riječi (Anić i Goldstein - I. izdanje 1998., II. izdanje 2000.); Hrvatski enciklopedijski rječnik (ur. odbor: Anić i dr. 2003.).

2 Ostale informacije iz rječničkih natuknica navode se u skraćenome obliku zbog uštede prostora. Definicije koje se analiziraju u radu su podcrtane.
} 
U ovome poglavlju analiziraju se primjeri leksikografske obrade osobnih zamjenica prvoga i drugoga lica jednine $(j a, t i)$. Osobna zamjenica ja kodira dvije informacije: komunikacijsku ulogu govornika te gramatičku kategoriju broja (jednine). Isto vrijedi za zamjenicu $t i$, odnosno mogućnost izbora oblika $t i / V i$, koji su ujedno i društveni deiktici. Analiza frekventnosti lema ti i ja u mrežnome korpusu $\mathrm{hrWaC}$ pokazala je da se osobna zamjenica ja po učestalosti upotrebe nalazi na 17. mjestu (6 671747 pojavnica), dok osobna zamjenica ti zauzima također visoko 46. mjesto (2 432297 pojavnica). Kao iznimno učestali, navedeni leksemi iziskuju podroban i sveobuhvatan leksikografski opis. U nastavku slijedi analiza rječničkih definicija primarnoga značenja osobnih zamjenica ja i $t i$ iz triju rječnika hrvatskoga jezika. Analiziraju se i ostale sastavnice njihova leksikografskoga opisa koje sadržavaju pragmatičke informacije.

\section{HJP}

jâ $-v$. ego

\section{RHJ}

jâ

1. lična zam. za 1. l.jd. <..>; ja (u raznim kontekstima iza glagola, tautološki kao riječ koja se odnosi na prethodno rečeno ili naglašava iskaz) [A: Vi imate kuću B: Nemam ja samo kuću nego i imanje, Znam ja što vi mislite meni je to jasno, ne sumnjate da mi nije jasno] [...]

[u nastavku su nabrojani sljedeći frazemi i kolokacije uz objašnjenja njihova značenja: ne znam ja; ne znam ja ništa; znam ja tebe (njega itd.); znam je sve; znam je što radim; imam ja; radim ja; ne radim ja; nisam ja taj (takav)]

2. ja pa ja $[\ldots]$

\section{VRH}

jâ

1. osoba koja govori ili piše, govoritelj [To je ono što ja znam.; Mene to ne zanima.; On mi je rekao.; Sa mnom si siguran.]

[u nastavku su nabrojani sljedeći frazemi i kolokacije uz objašnjenja njihova značenja i primjere upotrebe: ja pa ja, ja tebi ti meni, nemoj ti meni]

2. $<\mathrm{D} \mathrm{mi}>[\ldots]$

3. $<$ u im. službi $>[\ldots]$ 
Analiza leksikografskih natuknica za osobnu zamjenicu ja iz triju hrvatskih rječnika pokazala je sljedeće: (1) u HJP-u rječnička definicija izostaje; natuknica sadržava samo poveznicu na leksikografsku natuknicu za imenicu ego; (2) u RHJ-u je navedena tek sažeta metalingvistička gramatička definicija (lična zamjenica za prvo lice jednine) popraćena napomenom o funkcijama leksema u poziciji iza glagola (tautologija, naglašavanje); (3) u VRH-u je navedena opisna definicija leksema (osoba koja govori ili piše, govoritelj), koja korisnika navodi na pogrešan zaključak da su leksemi ja i govoritelj sinonimni. Uvođenjem pragmatičke perspektive u rječničku definiciju, koja bi eksplicitno ukazivala na deiktičnost leksema i njegovu autoreferencijalnu upotrebu, lako bi se izbjegle sve nejasnoće. Što se tiče priloženih primjera, u RHJ-u su navedeni isključivo primjeri upotrebe osobne zamjenice $j a$ u poziciji iza glagola. U VRH-u se navode dva takva primjera te dva stilski neutralna primjera.

Iz provedene analize proizlazi zaključak da su postojeći opisi osobne zamjenice ja nedostatni te da je nužna njihova dorada. Dok u HJP-u njezin opis u potpunosti izostaje, u drugim dvama rječnicima izostaje sustavan opis njezinih obilježja (pa tako i deiktičnosti), funkcija i upotrebe. Sličnomu zaključku vode i rezultati analize rječničkih definicija osobne zamjenice $t i$, čiji prikaz slijedi u nastavku:

\section{HJP}

tî 1. (lična za 2. 1. jd) [biti na ti s kim; davati ti kome obraćati se s „ti” i u jednini ob. a. među prijateljima i kolegama kao znak ravnopravnosti b. obraćanje starijega mlađemu kad su u istoj službi gdje vladaju takve navike c. kad je sugovornik znatno mlađi]

2. (u raznim kontekstima) uopćen subjekt u zn. „,svatko”, „čovjek” i sl. $[\ldots]$

[u nastavku su nabrojane sljedeće kolokacije i frazemi, objašnjenja njihova značenja i primjeri upotrebe: eto ti (sad), gle/vidi ti to, sve ti je to, svi su ti..., tako ti je (to), ti!, ti i tko te...]

\section{RHJ}

tî

1. lična zam. za 2. l.jd <...>

2. (u raznim kontekstima) uopćen subjekt u zn. „svatko”, „čovjek” i sl. $[\ldots]$

[u nastavku su nabrojane sljedeće kolokacije i frazemi, objašnjenja njihova značenja i odgovarajući primjeri upotrebe: eto ti (sad), gle ti to, znaj ti to (sad), sve ti je to, svi su ti..., tako ti je (to), ti i tko te... Na koncu se tumače izrazi biti na ti s kim ili davati ti kome, a definicija je identična onoj u HJP-u] 


\section{VRH}

tî

1.a. Osoba kojoj se govori ili piše, sugovoritelj s kojim je govoritelj blizak ili koja je dijete, podređeni ili vršnjak [Ti si svoje dobio.; Tebe se to ne tiče,; Rekao ti je.]

$\square$ biti na ti s čim dobro poznavati (znati, shvaćati) što

b. $<\mathrm{Ti}>$ u pismu onaj kojemu se govornik obraća s poštovanjem [Pišem $\mathrm{Ti}$ nakon dugo vremena.; Pozdrav Tebi i Tvojima] usp. vi.

2. $<\mathrm{ti}>$ a. [u službi posvojne zamjenice] [...]

b. $<\mathrm{D}>$ etički dativ $[\ldots]$

U HJP-u i RHJ-u rječničke natuknice o zamjenici $t i$ sadržavaju tek sažetu gramatičku definiciju (lična zamjenica za drugo lice jednine). U VRH-u je navedena opisna definicija koja sadržava pragmatičku informaciju o instanci sugovornika, ali ne i eksplicitnu informaciju o deiktičnosti izraza. Zbog toga drugi dio definicije (o upotrebi zamjenice s obzirom na društvene odnose među sugovornicima i situaciju govornoga događaja) nije posve jasan.

U mnogim su jezicima osobni deiktici ujedno i označivači društvenoga statusa i odnosa među sudionicima govornoga događaja. Tako se u nekim jezicima razlikuju osobne zamjenice kojima govornik oslovljava svojega sugovornika s obzirom na čimbenik bliskosti/distanciranosti. U slavenskim se jezicima društvena deiksa izražava na morfološkoj i leksičkoj razini (osobne zamjenice $t i / V i$ te njima odgovarajući glagolski oblici, vokativni izrazi i titule). Izbor osobne zamjenice u drugome licu uvjetovan je nizom složenih sociopragmatičkih zakonitosti: tema razgovora, društveni kontekst, dob i spol sudionika razgovora, njihovi srodstveni odnosi, pripadnost zajedničkoj dijalektalnoj ili društvenoj grupi, politički ili pravni autoritet jednoga od sudionika razgovora te emocionalna solidarnost među sugovornicima (Freidrich 1966).

U HJP-u i RHJ-u društvena deiktičnost zamjenice $t i$ spominje se tek kao popratni komentar uz izraze biti na ti s kim i davati ti kome, a kao čimbenici njezine upotrebe navode se dob i bliskost među sugovornicima. U VRH-u se društvena deiktičnost zamjenice $t i$ prikazuje u okviru definicije primarnoga značenja, a uz dob i bliskost među sugovornicima kao čimbenik upotrebe navodi se i njihov društveni status. Opis ovih sociopragmatičkih informacija o izboru i upotrebi leksema u trima analiziranim rječnicima sažet je i pojednostavljen. Smatramo da bi principi izbora i upotrebe osobnih zamjenica $t i / V i$ u jednojezičnim rječnici- 
ma hrvatskoga jezika trebali biti sustavno prikazani te da bi se njihov opis trebao zasnivati na korpusnoj (socio)pragmatičkoj analizi jezične upotrebe. ${ }^{3}$ Držimo da bi najprikladniji izvor za kvantitativnu analizu upotrebe ovih oblika bili korpusi govorenoga i pisanoga jezika.

\subsection{Mjesna, vremenska i diskursna deiksa: analiza primjera}

Mjesna deiksa podrazumijeva jezično kodiranje prostornih odnosa koji su relativni u odnosu na lokaciju sudionikā govornoga događaja. U većini svjetskih jezika gramatikalizira se distinkcija između proksimalnih odnosa (blizu govornika) i distalnih odnosa (daleko od govornika; u nekim slučajevima blizu sugovornika/slušatelja), dok se u nekima gramatikaliziraju i preciznije distinkcije (Levinson 1983: 62). Kad je riječ o mjesnoj deiksi, Yule (1996: 13) ističe da može biti uvjetovana prostornim i mentalnim relacijama (npr. emocionalna ili temporalna proksimalnost/distalnost). Budući da je u jezik upisan čovjekov biološki ustroj, njegovo okruženje, fizička obilježja, način kretanja i trodimenzionalno poimanje prostora, organizacija mjesne deikse je antropocentrična (Lyons 1975: 690). Za ispravnu interpretaciju mjesnih deiktika uz poznavanje konteksta u kojemu se odvija govorni događaj potrebna je i primjena enciklopedijskoga i jezičnoga znanja. Jezično znanje pritom podrazumijeva poznavanje pragmatičkih pravila upotrebe mjesnih deiktika. Isto vrijedi i za ostale vrste deiktika.

Mjesna deiksa u hrvatskome se jeziku izražava različitim jezičnim sredstvima: (1) ,pravim deikticima”: mjesni prilozi (npr. ovdje, tu, ondje, lijevo, desno, gore, dolje), pokazne pridjevske i imeničke zamjenice (to/ovo/ono, taj/ovaj/onaj - u oblicima za sva tri gramatička roda u jednini i množini) te pojedini glagoli kojima se kodira lokacija govornika i sugovornika (doći/otići, donijeti/odnijeti); te (2) nedeiktičkim izrazima modificiranim/determiniranim nekim deiktičnim jezičnim sredstvom (npr. ova strana ploče, desna vrata). Upotreba mjesnih deiktika može biti simbolička ili gestovna.

U ovome poglavlju slijedi analiza rječničkih opisa mjesnoga priloga ovdje. Analiza učestalosti upotrebe leme ovdje u mrežnome korpusu $h r W a C$ pokazala je da

\footnotetext{
Metodologija provođenja kvantitativne, korpusnopragmatičke analize pisanoga jezika detaljno je prikazana na primjeru diskursnoga deiktika dakle u članku Karlić i Bago 2019.
} 
se nalazi na 263. mjestu (430 908 pojavnica). Prilogom ovdje govornik označava lokaciju na kojoj se nalazi prilikom iznošenja iskaza. U pisanoj jezičnoj produkciji upotreba priloga ovdje u pravilu je simbolička, osim u nekim iznimnim slučajevima (npr. na internetskim stranicama: klikni ovdje + vizualna signalizacija kao gesta). Prostorni radijus koji prilog ovdje može „zahvaćati” uvelike varira. On, naime, u govornome događaju kodira lokaciju govornika, ali na vrlo neprecizan način - može se odnositi na jednu točku u prostoru ili na velik prostor $\mathrm{u}$ kojem se govornik nalazi (Ovdje je lijepo $\rightarrow \mathrm{u}$ krevetu, $\mathrm{u}$ stanu, $\mathrm{u}$ gradu, $\mathrm{u}$ državi, na kontinentu, na planeti itd.). U nastavku slijedi prikaz rječničkih opisa leksema ovdje:

\section{HJP/RHJ}

óvdje $<$ pril. $>$

na ovome mjestu

1. gdje je onaj koji govori

2. gdje su zajedno govornik i sugovornik

[u nastavku su nabrojani sljedeći frazemi i kolokacije, objašnjenja njihova značenja i primjeri upotrebe: ovdje-ondje, (e) ovdje mi sjedi / ovdje mi je sjelo, ovdje mi se popelo]

\section{VRH}

ovdje pril. <óvdje>

na ovome mjestu, na mjestu na kojemu se nalazi govoritelj [Budi sad ovdje.; Ovdje smo sigurni.; Ovdje ti je dobro.] $\neq$ ondje

[u nastavku su nabrojani sljedeći frazemi i kolokacije, objašnjenja njihova značenja i primjeri upotrebe: ovdje-ondje, ovdje mi se popelo / ovdje mi sjedi (mi je sjelo)]

Rječničke natuknice iz HJP-a i RHJ-a sadržavaju dvije vrste definicija leksema ovdje: (1) sinonimni deiktički izraz (na ovome mjestu) i (2) opisnu definiciju s pragmatičkom informacijom o lokaciji govornika, ali bez eksplicitne informacije o njegovoj deiktičnosti (gdje je onaj koji govori). U VRH-u su te dvije vrste definicija povezane u jedinstvenu definiciju. U HJP-u i RHJ-u navedena je i opisna definicija koja sadržava informaciju o lokaciji sugovornika ( gdje su zajedno govornik $i$ sugovornik), no nije popraćena nikakvim dodatnim pojašnjenjem, pa je odnos između prve i druge definicije nerazjašnjen. Izostanak informacije o deiktičnosti izraza u svim trima analiziranim rječnicima može navesti korisnika na pogrešan zaključak da se prilogom ovdje označava lokacija bilo kojega 
govornika (i sugovornika), a ne isključivo govornika koji koristi navedeni izraz. Ilustrativan primjer upotrebe priloga ovdje te njegov antonim (ondje) izneseni su jedino u VRH-u.

Analizom rječničkih natuknica za prilog ovdje utvrdile smo problem cirkularnosti i dvosmislenosti definicija te izostanak informacija o: (1) gestovnoj upotrebi leksema (koja se sugerira primjerima ovdje mi se popelo i ovdje mi je sjelo); (2) diskursnoj deiktičnosti leksema (Ovdje raspravljamo o rječničkim opisima deiktika.); (3) varijabilnosti opsega prostora koji leksem može označavati; (4) mogućnosti nedeiktičke upotrebe leksema (koja se sugerira primjerom ovdje-ondje). Smatramo da je revizija postojećih leksikografskih opisa ovoga deiktika nužna, a trebali bi sadržavati metalingvističku pragmatičku definiciju koja sadržava informaciju o deiktičnosti i upotrebi leksema (npr. prilog kojim govornik označava mjesto na kojem se nalazi za vrijeme iznošenja iskaza), kao i informacije o gorenavedenim pragmatičkim obilježjima i funkcijama leksema, popraćene odgovarajućim ilustrativnim primjerima upotrebe leksema. Svi podatci trebali bi biti zasnovani na rezultatima provedene pragmatičke analize pisanih i govorenih korpusa hrvatskoga jezika.

Vremenska deiksa odnosi se na jezično kodiranje vremenskih točaka/raspona relativnih s obzirom na vrijeme iznošenja iskaza, a zasniva se na interakciji između deiktičkih koordinata i nedeiktičke konceptualizacije vremena i prostora (Levinson 1983: 73). Kao i sve druge vrste deikse, vremenska je deiksa usko povezana s ulogama sudionika govornoga događaja - pošiljatelja i primatelja iskaza. Uslijed neposredne komunikacije vrijeme kodiranja i primanja poruke je simultano. Mehanizam (de)kodiranja se, međutim, usložnjava u slučajevima deiktičke nesimultanosti (Fillmore 1971), kao što je to primjerice slučaj prilikom čitanja memoara ili pisama. Psihološka baza temporalne deikse slična je onoj mjesne deikse (Yule 1996: 14). Njihovo je zajedničko obilježje „kretanje” objekata/događaja prema govorniku ili udaljavanje od njega - u prostoru, vremenu ili na neki drugi način.

Vremenska deiksa u hrvatskome se jeziku izražava različitim jezičnim sredstvima: (1) „pravim deikticima”: vremenski prilozi (npr. prije, sada, poslije, jučer, danas, sutra) i deiktični pozdravi (npr. dobro jutro, dobar dan, dobra večer) te (2) nedeiktičkim izrazima modificiranim nekim deiktičnim jezičnim sredstvom (npr. sutrašnji sastanak, prošla godina) ili determiniranim pokaznim zamjeni- 
cama, kojima se izražava vremenska proksimalnost ili distalnost (npr. ovo popodne, onaj tjedan). I glagolska vremena kojima se gramatikalizira odnos između sidrišta vremenske deikse i vremena radnje smatraju se deiktičkim jezičnim sredstvima.

U ovome poglavlju slijedi analiza rječničkih opisa vremenskoga priloga $\operatorname{sad}(a)$. Analiza njegove frekventnosti u mrežnome korpusu $\mathrm{hrWaC}$ pokazala je da se sad nalazi na 110. mjestu (996 389 pojavnica), a sada na 112. mjestu (991 948 pojavnica). ${ }^{4}$ Prilogom sad(a) govornik označava vrijeme u kojemu iznosi iskaz. U pisanoj jezičnoj produkciji prilog sad(a) ne može biti u gestovnoj upotrebi, dok u govorenoj može (Kreni... sad!). Vremenski raspon koji prilog sad(a) može „zahvaćati” uvelike varira - može se odnositi na jedan trenutak ili duže razdoblje (Sada je sve bolje $\rightarrow$ u ovome trenutku, ove godine, u ovome stoljeću itd.). U nastavku slijedi prikaz rječničkih opisa leksema $\operatorname{sad}(a)$ :

\section{HJP}

säd (säda) < pril.>

1. u ovo vrijeme, u ovaj čas, trenutak

2. malo prije

3. kao riječ koja najavljuje neodređeno oklijevanje ili ono što će biti [...]

4. u raznim kontekstima [pod ovom su točkom nabrojani sljedeći frazemi i kolokacije, objašnjenja njihova značenja i primjeri upotrebe: sad ću, eto (evo) ga sad, vidi sad, gle sad, gle sad ovo (to), i sad znaj, i sad je to...]

\section{RHJ}

säd (säda) < pril.>

1. u ovo vrijeme, u ovaj čas

2. malo prije ili poslije [sad je bio ovdje, sad ću (doći)]

3. oklijevanje $[\ldots]$

4. (u raznim kontekstima) [pod ovom su točkom nabrojani sljedeći frazemi i kolokacije, objašnjenja njihova značenja i primjeri upotrebe: sad ću, eto (evo) ga, vidi (ga) sad, gle sad, gle sad ovo (to), i sad znaj, i sad je to..., pa sad, kad ćeš ako sad nećeš, (e) sad, šta sad]

\section{VRH}

sâd $<$ pril.>

1. u ovome trenutku, u trenutku u kojemu govoritelj govori [sad me svi slušaju.; sad spava.]

4 Ako se zbroji broj pojavljivanja pojavnice sad i sada, pojavnica se nalazi između 57. i 58. mjesta. 
$\square$ [pod ovom su točkom nabrojane sljedeće kolokacije, objašnjenje njihova značenja i odgovarajući primjeri: sad ... sad, i sad, kad ćeš ako sad ne ćeš, sad ili nikad, (i) šta sad]

2. malo prije [Sad su otišli.; Sad smo se sve dogovorili] $\rightarrow$ upravo

3. u bliskoj budućnosti [Sad ću krenuti.; Sad dolazim.; Sad ću. (na poziv ili požurivanje) u značenju dolazim, evo me] $\rightarrow$ isti čas \{čas\}, upravo, uskoro

U svim trima rječnicima natuknica za prilog $\operatorname{sad}(a)$ sadržava definicije primarnoga i sekundarnoga značenja koje se sastoje od sinonimnih deiktičnih izraza (u ovome trenutku; malo prije/poslije). Jedino je u VRH-u sinonimska definicija primarnoga značenja dopunjena pragmatičkom informacijom o govornikovoj perspektivi kodiranja podatka o vremenu na koje se prilog odnosi, no na prilično nespretan način. U sklopu iste definicije izmjenjuju se dvije perspektive (sinonimska i metalingvistička: $u$ ovome trenutku / u trenutku u kojemu govoritelj govori), što definiciju čini nejasnom.

Analizom navedenih rječničkih natuknica za prilog $\operatorname{sad}(a)$ utvrdile smo iste probleme kao u rječničkim opisima priloga ovdje, u kojima se ne prikazuje: (1) mogućnost gestovne upotrebe leksema; (2) diskursna deiktičnost leksema (Sada ćemo iznijeti primjer diskursne deikse.); (3) varijabilnost raspona vremena koje leksem može označavati; (4) mogućnost nedeiktičke upotrebe leksema (koja se sugerira primjerom sad ili nikad). Smatramo da je revizija postojećih leksikografskih opisa ovoga deiktika nužna jednako kao i u slučaju priloga ovdje.

$$
* * *
$$

Diskursna deiksa podrazumijeva kodiranje, odnosno referiranje na određene dijelove diskursa u sklopu kojega se ostvaruje iskaz (Levinson 1983: 64). Budući da se diskurs odvija u vremenu, referiranje na elemente diskursa uglavnom se ostvaruje s pomoću vremenskih deiktika (koji su nerijetko svojim porijeklom mjesni deiktici). Prototipni centar diskursne deikse govornikova je pozicija u diskursu prilikom iznošenja iskaza. Diskursna deiksa ne podrazumijeva samo kodiranje jezičnih sastavnica nego i širega konteksta u kojemu se iskaz producira - događanja i okolnosti vidljivih/poznatih sudionicima govornoga događaja (Fillmore 1975: 70) (npr. Ovo je bilo zanimljivo.).

Diskursna deiksa u hrvatskome se jeziku izražava vremenskim i mjesnim deikticima kojima se kodira govornikova (u rjeđim slučajevima i sugovornikova) 
pozicija u sklopu tekućega diskursa. Njihov izbor i upotreba u nekim slučajevima nisu zadani vremenskom, nego grafičkom organizacijom teksta (npr. donji pasus, gore navedene tvrdnje). Funkciju diskursnih deiktika vrše i diskursni markeri - riječi i fraze koje označavaju odnos između iskaza i prethodnoga/ nadolazećega diskursa (npr. dakle, međutim, osim toga, na koncu). U nekim jezicima postoje specifična jezična sredstva kojima se označavaju tema i/ili rema u rečenici (kao što je to slučaj u japanskome), dok se u hrvatskome ta informacija u nekim slučajevima kodira redom riječi.

Iako mjesni deiktik ovdje i vremenski deiktik sad(a) u hrvatskome jeziku vrše funkciju diskursnoga deiktika, to se obilježje ne navodi u njihovim rječničkim opisima. Smatramo da bi se opis i primjeri ove njihove funkcije trebali temeljiti na podacima dobivenim pragmatičkom analizom korpusa pisanoga jezika.

\section{Zaključci}

Iz analize leksikografske obrade primjera osobnih, društvenih, mjesnih, vremenskih i diskursnih deiktika ( $j a, t i \neq V i$, ovdje, sad/a) u trima jednojezičnim rječnicima hrvatskoga suvremenog književnog jezika (HJP, RHJ, VRH) proizlaze sljedeći zaključci:

(1) Rječnički opisi deiktika na granici punoznačnosti u hrvatskim su jednojezičnim rječnicima nedostatni: njihove rječničke definicije cirkularne su i dvosmislene te ne uključuju nužne pragmatičke informacije o deiktičnosti, funkcijama i upotrebi leksema.

(2) Smatramo da bi primarno značenje deiktičnih izraza u rječnicima trebalo biti prikazano metalingvističkim definicijama kojima se opisuje njihova funkcija i mehanizam uspostavljanja značenja odnosno identifikacije referenta. ${ }^{5}$ Primjerice:

(a) $j a$ - riječ kojom se govornik referira na samoga sebe

\footnotetext{
5 Metalingvističke definicije deiktika zastupljene su u nekim rječnicima stranih jezika novijega datuma, posebice onima namijenjenim neizvornim govornicima. Primjerice, Gyurjyanova analiza jednojezičnih rječnika engleskoga jezika (Gyurjyan 2018) pokazala je njihovu visoku zastupljenost u rječniku Collins COBUILD Advanced Learner's Dictionary (2014). Tu vrstu definicija deiktika u pravilu ne nalazimo u sklopu rječničkih opisa deiktika u jednojezičnim rječnicima hrvatskoga i drugih južnoslavenskih jezika.
} 
(b) $t i / V i$ - riječ kojom se govornik referira na svojega sugovornika

(c) ovdje - riječ kojom govornik označava mjesto na kojemu se nalazi prilikom iznošenja iskaza

(d) sada - riječ kojom govornik označava vrijeme u kojemu iznosi iskaz.

Metalingvistička definicija trebala bi biti popraćena odgovarajućim ilustrativnim primjerima i uputama za upotrebu leksema. Rječnički opis deiktika trebao bi obuhvaćati sve (ili barem najučestalije) njihove funkcije i glavna svojstva. U slučaju polifunkcionalnih izraza njihove bi funkcije trebale biti poredane prema kriteriju učestalosti upotrebe.

(3) Smatramo da bi se rječnički opisi deiktika trebali zasnivati na korpusnoj pragmatičkoj analizi pisane i/ili govorene jezične građe, kojom bi se utvrdila svojstva i funkcije deiktika te obilježja i frekventnost njihove upotrebe. Leksikografski opisi deiktika u jednojezičnim rječnicima trebali bi sadržavati pragmatičke informacije, a sredstva i načini njihove prezentacije u rječnicima trebali bi se primjenjivati na sustavan i dosljedan način.

Valja naglasiti da pragmatičke informacije o riječima - osim u sklopu definicija i s pomoću ilustrativnih primjera - u rječničkim opisima mogu biti prikazane i drugim sredstvima, kao što su primjerice rječničke odrednice. Međutim, rječničke definicije popraćene ilustrativnim primjerima smatramo najprikladnijim sredstvom opisa pragmatičkih informacija o deiktičnim izrazima.

Ovaj rad predstavlja polazište za daljnja istraživanja o primjenjivosti (korpusne) pragmatike u leksikografiji. Smatramo da se uvođenjem pragmatičke perspektive u leksikografsku obradu deiktika (kao i drugih riječi s pragmatičkim funkcijama) uvelike može povećati kvaliteta njihovih rječničkih opisa.

\section{Izvori}

Anić, Vladimir. 1998. Rječnik hrvatskoga jezika. Novi liber. Zagreb.

Hrvatski jezični portal / Croatian Language Portal. http://hjp.znanje.hr (pristupljeno 12. kolovoza 2019.).

JoJIĆ, LJILJANA (ur.). 2015. Veliki rječnik hrvatskoga standardnog jezika. Školska knjiga. Zagreb.

LuUbeší́, Nikola; KlubičKa, Filip. 2016. Croatian web corpus hrWaC 2.1. Slovenian 
language resource repository CLARIN.SI. http://hdl.handle.net/11356/1064 (pristupljeno 12. kolovoza 2019.).

\section{Literatura}

Audi, Robert; Audi, Paul (ur.). 1999. The Cambridge dictionary of philosophy. Cambridge University Press. Cambridge.

BüHLER, KARL. 1934. Sprachtheorie. Vol. 2. Fischer. Jena.

Diessel, Holger. 2012. Deixis and demonstratives. An international handbook of natural language meaning 3. 2407-2431.

Dylgjeri, Ardita; Kazazi, Ledia. 2013. Deixis in modern linguistics and outside. Academic Journal of Interdisciplinary Studies 2/4. 87-96.

Fillmore, Charles J. 1975. Santa Cruz Lectures on Deixis 1971. Indiana University Linguistics Club. Bloomington.

Friedrich, PAUl; Bright, William. 1966. Structural implications of Russian pronominal usage. Mouton. Hague - Paris.

Gyurjyan, Tatev. 2018. Pragmatic Information in Dictionary Definitions of Deictic Words. The International Journal of Communication and Linguistic Studies 16/1. 1-9. doi.org/10.18848/2327-7882/CGP/v16i01/1-9.

Kaplan, David. 1989. Demonstratives: an essay on the semantics, logic, metaphysics, and epistemology of demonstratives. Themes from Kaplan. 481-563.

Karlić, Virna; Bago, Petra. 2019. Representation and Classification of Polyfunctional Synsemantic Words in Monolingual Dictionaries and Language Corpora: The Case of the Croatian Lexeme Dakle. Electronic lexicography in the 21st century. Proceedings of the eLex 2019 conference. Ur. Kosem, Iztok i dr. Lexical Computing CZ s.r.o. Brno. 99-115.

Kordić, SnJežAnA. 2002. Riječi na granici punoznačnosti. Hrvatska sveučilišna naklada. Zagreb.

Levinson, Stephen C. 1983. Pragmatics. Cambridge University Press. Cambridge.

Levinson, Stephen C. 2004. Deixis and pragmatic. The Handbook of Pragmatics. Ur. Horn, Laurence R.; Ward, Gregory. Blackwell. Oxford. 97-121.

Lyons, John. 1977. Semantics. Vol. 2. Cambridge University Press. Cambridge.

Tomasello, Michael. 2006. Why don't apes point?. The Roots of Human Sociality: Culture, Cognition, and Interaction. Ur. Enfield, Nick J.; Levinson, Stephen. Berg. Oxford. 506-524.

Yule, George. 1996. Pragmatics. Oxford University Press. Oxford. 


\title{
Pragmatics and Lexicography: Deixis as a Challenge of Contemporary Lexicography
}

\begin{abstract}
The paper deals with the problem of the lexicographic description of deictic expressions in contemporary monolingual dictionaries of the Croatian language. The term "deixis" refers to a group of language units that indicate elements of situational and/or discourse context in the utterance-such as participants, time, and place of the speech event (Lyons 1977). Deictic expressions belong to a group of lexemes that are especially challenging for lexicographers because their full meaning or referent is established or identified only within the specific speech event. For these reasons, the characteristics of deixis are a constant reminder of the fact that natural languages were primarily designed for use in face-to-face interaction, and that a language can only be analyzed to a certain extent without taking into account these facts (Levinson 1983). In this paper, we conduct an analysis of the definitions of meanings and descriptions of the functions of deictic expressions in Croatian lexicography based on selected representative examples of personal, temporal, spatial, discourse, and social deixis. We identify the shortcomings of the selected dictionaries and suggest possible solutions to the identified problems by applying the methods of corpus pragmatics.
\end{abstract}

Ključne riječi: deiksa, pragmatika, korpusna pragmatika, leksikografija, hrvatski jezik Keywords: deixis, pragmatics, corpus pragmatics, lexicography, Croatian language 


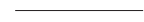

